\title{
Research Agenda in Medical Sociology
}

\author{
Hannah Bradby* \\ Uppsala University, Uppsala, Sweden
}

Keywords: medical sociology, social processes, health and illness, socialized national health systems, socioeconomic production of illness, transnational medical markets

Sociology queries taken for granted understandings of the world and especially those that claim universal applicability, but that in fact support particular interests. In showing up the hidden workings of power - the interests of institutions, professions, corporations, and capital - the complex set of interests that make up modern medicine can be explored to disrupt simplistic accounts of its beneficence. By seeing health and illness as social as well as individual bodily processes, and conceptualizing medicine as a practice and profession that is entangled with governance and speculative capital, sociology offers critical insights to medicine's curative and therapeutic benefits (Bradby, 2012). The challenge for a progressive sociology of medicine is to critique the range of interests that make up medicine (as profession, discipline, business, statutory, and non-governmental institution across the world) while holding a sense of medicine's benefits and deficits at individual and population level in balance with other knowledge systems and moralities of healing.

From the height of the industrial revolution onward, the ill effects of poor living conditions on people's health have been documented (Engels, 2001; Collyer, 2015). With sociology's arrival as a University discipline at the start of the twentieth century, medicine was not viewed as a key institu-

OPEN ACCESS

Edited by:

Maria Clasina Stuttaford, University of Cardiff, UK

Reviewed by: Gillian Ann Hundt,

University of Warwick, UK

${ }^{*}$ Correspondence: Hannah Bradby hannah.bradby@soc.uu.se

Specialty section: This article was submitted to Medical Sociology, a section of the journal Frontiers in Sociology

Received: 26 July 2016 Accepted: 28 September 2016 Published: 20 October 2016

Citation:

Bradby H (2016) Research Agenda in Medical Sociology. Front. Sociol. 1:14. doi: 10.3389/fsoc.2016.00014 tion, alongside religion, the law and the family, in understanding modernity. However, with the delineation of medicine's role as a social system responsible for deviance and social control (Parsons, 1991), medicine's implications in modernity's development became the research tradition we now call medical sociology. Interrogation of medical organization and processes show their implication in the nation state's technology of power (Rose, 2007), an insight which recasts medicine's relationships with patients and populations in terms of iatrogenesis (Illich, 1977), medicalization (Conrad, 2005; Conrad et al., 2010), and surveillance (Foucault, 1979). The insight that health is socially produced, and its distribution across class, gender, and generation can be measured to show inequalities in morbidity and mortality, has shaped the policy and practice of national health and welfare organizations. Bourdieu's model of social capital, conceptualizing the institutionalization of power, across statutory, market, and familial structures problematizes a simple account of tackling health inequalities through changing individual health behaviors (Carpiano, 2007).

The contradiction between public health's approach to population health and clinical medicine's focus on individual bodies is epitomized by the herd immunity conferred by mass immunization programs for infectious disease, reducing the urgency for individual immunization. Sociological investigation of the decisions that parents make regarding their children's immunization renders visible the various understandings of risk in operation (Casiday, 2007). Giving credence to nonprofessional priorities in treatment and prevention is part of the erosion of medical dominance (Freidson, 1988) that has been underway since the (possibly apocryphal) Golden Era of physician power. Sociological research has explored these various challenges to medical power, through the rise of other professions (management, nursing), other healing systems, expert patients, as well as commercial and legal interests (Williams and Calnan, 1996). Evidence-based medicine, using metaanalyses to apply systematic assessment of research results to clinical decision-making, the rise of evidence to inform practice, evaluation, and commissioning of services has become mainstream. 
While sociological research has influenced the context and development of medical practice, its analyses have been largely confined to Western democracies' health and welfare systems. Sociology's slowness to engage with health and illness beyond the Global North, where medicine is differently configured and regulated, denotes a Euro-centrism that relinquishes analytic responsibility to other disciplines such as anthropology, development studies, and international public health. A partitioning off of the social processes of health and illness in the Global South implies that different processes pertain that these might even require different sorts of medicine. While sociology has criticized the universality of medical knowledge claims, it has failed to illuminate the transnational flows of capital, labor, and ideas that create national health systems, thereby supporting the imagined community of the nation state (Anderson, 1991). The nation state has regulated health-care spending in favor of orthodox medicine such that the plurality of approaches to supporting and enhancing health is particularly apparent beyond the welfare states of the Global North. Researching plural approaches to health and illness shows how medical understandings are combined with, changed and subsumed by other models in different settings. Such research opens up a wider culture of health and illness to view, as well as illuminating the particularities of the culture of medicine.

Despite, but also thanks to sociological critique, scientific medicine has become the most authoritative source of evidence and intervention to promote health for individuals and for populations, worldwide. The provision of good quality accessible medical treatment to support health is a high priority for individuals and for societies - an ideal that people will vote for, pay for, campaign for - a highly potent force, politically, financially, and morally. The association between medicine and good health, in national health systems and in markets, is based on an idea of medicine's therapeutic efficacy for bodily and psychic suffering. The epitome of medical curative potential crystallized in the mid-twentieth century, when the research and development opportunities of two World Wars helped bring antibiotics, new surgical techniques, steroids, and insulin to the general public. The contraceptive pill was developed, while smallpox and polio vaccination programs were eradicating infectious disease. A pill for every ill: cures that work regardless of the patient's faith in the supernatural order or their social status and independent of the affect of the doctor and patient. Silver-bullet cures that are consistently and universally efficacious: antibiotics to cure blood poisoning in Scandinavia and Sumatra, regardless of the rank and association of those administering and receiving treatment, not only universally applicable but also consistently efficacious. The twentieth century's establishment of socialized national health systems and social security extended such efficacious medicine to people without means to pay, with access to medical services coming to be seen as a human right.

Despite high expectations, silver-bullet cures have not materialized for emergent (bird flu, Zika, Ebola), let alone familiar pathogens (the common cold, HIV, herpes) (Crawford, 2000). Non-communicable diseases - obesity, diabetes, some cancers, and auto-immune disorders - elude the one-shot silver-bullet cure, as do the common problems that account for days off work and health-care consultations - chronic back pain and depression.
While epidemiological methods have demonstrated exposure to tobacco and asbestos as unequivocally linked to disease, other risk factors, such as alcohol, fat, sunlight, and sedentary lifestyle, have more complex dose related and contingent effects on the risk of developing disease. And demonstrating a risk factor is not the same as establishing an effective therapeutic regime. Even when a silver-bullet cure is identified, whether it can be successfully deployed in the complex social, economic, political, and cultural context of everyday life requires other sorts of knowledge. The HIV epidemic showed us that highly effective interventions such as condom use did not work without an understanding of the priorities and values that informed people's sexual behavior. For instance, it was not only men who identified as gay or bisexual who were having unprotected anal sex and this sociological understanding pointed to the wives and girlfriends of "straight" men (who had sex with men) who were also at risk from HIV infection.

Systematic reviews of evidence to inform health care have not only illuminated the complexities of the socio-economic production of illness but also the costs and benefits of therapy and care. In establishing shared standards and guidelines for health care, anomalies stand out. Comorbidity and multimorbidity present particular challenges for standardized care pathways: with more than two conditions, treatment interactions become hugely complex. Iatrogenic problems, where medical intervention harms through error, side-effect, addiction, and drug interactions are part of the cost of medicine. Some medical treatments are aimed at neither disease nor injury: infertility, body dysmorphia, and forms of sexual dysfunction are treated through surgical and pharmacological intervention. As a professional strategy, diagnosing quotidian discontents with medical terminology offers a guaranteed stream of patients. While professional ambition and commercial gain have been part of the development of medicine's role in society, another element is the collective appetite for medical attention to our disease, both collective and individual. Medicine addresses ills - despair, anti-social behavior, and alcoholism - that a priest or police officer attended to in previous eras, as well as problems such as insomnia and impotence that may once have remained private. Medicalization of social, psychological, spiritual, and existential problems means that medicine treats forms of suffering for which its methods are ineffective.

The monopolies that medical associations gained in the nineteenth century (despite a lack of demonstrably efficacious therapies at that time) led to the profession's influence in designing the structures of national health systems in the twentieth century. Improving population health through extending access to health services became a priority for newly enfranchised groups. The public health systems were working toward improved individual AND population health outcomes, goals which can be at odds with one another. Risk calculations enumerate the uncertain outcomes for populations and by extension, for individuals. The translation of population-based odds ratios to advice for clinical consultations with individuals has proven problematic both in terms of technical difficulties of explicating the significance of a risk calculation and the delicacy of applying it to a person's particular circumstances and values. The spread of standardized means of measuring health-care's effectiveness since the 1990s has 
transformed idiosyncratic and uneven clinical decision-making, using the rationale of cost-benefit analyses. This transformation has been thorough-going to the extent that the limits of evidencebased methods are becoming apparent: minority populations who are under represented in trials, interventions, or surveys have no voice in these collated data. Sole reliance on systematic reviews and meta-data means compounding social exclusion of marginalized and mobile groups by covering the exclusion that they experience from the evidence base with a claim of universality. Values that are important to clinical decision-making and health policy may not be revealed by randomized control trials of interventions, as demonstrated by the role of health-care chaplains (ordained and otherwise) in contemporary national health services, to support the "spiritual wellbeing" of staff and patients.

Groups that are excluded through discrimination, poverty, migrant status, or stigma do not necessarily benefit from health systems that are designed for the average of a national population. The assumptions of the post World War II settlement about a nationally bounded, homogenous, stable citizenry have been undone by the persistence of mobility as a human strategy, alongside the increased ease of movement for capital, technology, and information. Medicine's reputation for therapeutic efficacy has been at the heart of financial speculative investment in biotechnology, pharmacology, and clinical care personnel and organizations. High tech innovations: genetic sequencing to permit individually tailored medical treatment, CT scans to detect inner lesions, and implanted defibrillators to prevent heart problems all suggest the potency of scientific medicine to fix our problems and create the necessary expectations for lucrative medical markets to flourish. These transnational medical markets can be understood in contradistinction to the nationally bounded public health systems, which explicitly exclude patients on the basis of their marginal migration status.

Medical sociology has flourished as a subspecialty of sociology with multiple constituencies in need of critical perspectives to make sense of their practice and perceptions: professions associated with medicine (radiology, nursing, physiotherapy) experience the contradictions of medicine as the dominant profession for promoting and preserving health. Decades of medical sociological research have shown us that the business of health is not the prerogative of medicine and that despite the great success of certain forms of medicine, there is much that does not work. Furthermore, the application of medical therapy and technology requires sociological understanding in order to be effective. Despite evident limitations, medical models of health and the suffering associated with illness have trouble accommodating alternative view points or experiences that do not conform to scientific standards of evidence. The practice of medicine is a human art of healing, requiring trust and empathy.

\section{REFERENCES}

Anderson, B. (1991). Imagined Communities: Reflections on the Origin and Spread of Nationalism, rev and extended Edn. London: Verso.

Bradby, H. (2012). Medicine, Health and Society: A Critical Sociology. London: SAGE. Available at: http://www.uk.sagepub.com/booksProdDesc.nav?prodId= Book228897
Evidenced-based medicine is a means to ration access to treatment where the evidence-base is scientific and mostly quantitative (although methods for systematic reviews of qualitative evidence are developing). The value-neutral truth of science over-rides other forms of knowledge such as intuition, tradition, or faith. The question of how alternative forms of evidence can be incorporated into or accommodated alongside modern medical practice is urgent. The widening participation agenda raises the question of making sense of non-scientific evidence and lay knowledge and are important in terms of medicine's relationship with knowledge systems from beyond the Global North. The apparent certainty of science is extremely appealing compared with the vicissitudes of suffering and illness. Humanity's desire to avoid illness and promote health means that medicine's therapeutic reputation is a powerful marketing tool for technology, medication, and intervention to fix our problems and address our suffering in a global market. The vision of good health for individuals and populations is not only a powerful driver of commerce but also informs demands for access to health care as a human right. Biomedicine is a powerful marketing method and informs the widening provision of health care but sociological insight is needed for effective applications of medical solutions and for widespread access to the socio-economic and cultural determinants of health.

The mismatch between the complexities and diversities of human experience, on the one hand, and the certainty of scientific solutions, on the other, some of which are profitable, offers territory for an imaginative progressive sociology to explore. Sociology as a science of society has a broad remit requiring an ongoing commitment to interdisciplinary discussion covering theory, methods, and empirical material. The challenge for sociology is to continue its critical approach to interrogating the social processes of health and illness, to contribute to more humane, equitable, and effective healing that integrates scientific evidence with people's values and experience. To perform a critical role with an appreciation of medical progress alongside an understanding of how the application of medical science plays out in daily lives beyond the Global North is the demanding undertaking to which this journal aspires to contribute.

\section{AUTHOR CONTRIBUTIONS}

The author confirms being the sole contributor of this work and approved it for publication.

\section{ACKNOWLEDGMENTS}

Many thanks to Maria Stuttaford and Gillian Hundt for helpful responses to the first draft.

Carpiano, R. M. (2007). Neighborhood social capital and adult health: an empirical test of a Bourdieu-based model. Health Place 13, 639-655. doi:10.1016/ j.healthplace.2006.09.001

Casiday, R. E. (2007). Children's health and the social theory of risk: insights from the British measles, mumps and rubella (MMR) controversy. Soc. Sci. Med. 65, 1059-1070. doi:10.1016/j.socscimed.2007. 04.023 
Collyer, F. (2015). "Karl Marx and Frederich Engels: capitalism, health and the healthcare industry," in The Palgrave Handbook of Social Theory in Health, Illness, and Medicine, ed. C.Fran (Basingstoke, Hampshire: Palgrave Macmillan), 35-58.

Conrad, P. (2005). The shifting engines of medicalization. J. Health Soc. Behav. 46, 3-14. doi:10.1177/002214650504600102

Conrad, P., Mackie, T., and Mehrotra, A. (2010). Estimating the costs of medicalization. Soc. Sci. Med. 70, 1943-1947. doi:10.1016/j.socscimed.2010. 02.019

Crawford, D. H. (2000). The Invisible Enemy: A Natural History of Viruses. Oxford: Oxford University Press.

Engels, F. (2001). The Condition of the Working Class in England/cFrederick Engels. London: Electric Book Co. Available at: http://ezproxy.its.uu.se/login?url=http://site.ebrary.com/lib/uppsala/Top?id=2001797

Foucault, M. (1979). Discipline and Punish: The Birth of the Prison. New York: Vintage Books.

Freidson, E. (1988). Profession of Medicine: A Study of the Sociology of Applied Knowledge, ed. University of Chicago Press (Chicago: University of Chicago Press).
Illich, I. (1977). Limits to Medicine: Medical Nemesis: The Expropriation of Health. Harmondsworth: Penguin.

Parsons, T. (1991). The Social System, 2 Edn, ed. Routledge Sociology Classics (London: Routledge).

Rose, N. (2007). Politics of Life Itself: Biomedicine, Power, and Subjectivity in the Twenty-First Century. Princeton: Princeton University Press.

Williams, S., and Calnan, M. (1996). Challenging Modern Medicine. London: UCL Press.

Conflict of Interest Statement: The author declares that the research was conducted in the absence of any commercial or financial relationships that could be construed as a potential conflict of interest.

Copyright (c) 2016 Bradby. This is an open-access article distributed under the terms of the Creative Commons Attribution License (CC BY). The use, distribution or reproduction in other forums is permitted, provided the original author(s) or licensor are credited and that the original publication in this journal is cited, in accordance with accepted academic practice. No use, distribution or reproduction is permitted which does not comply with these terms. 